\title{
Irrigation influences on summer stream temperature variability
}

\author{
Sara Alger ${ }^{1}$, Belize Lane ${ }^{1}$, and Bethany Neilson ${ }^{1}$ \\ ${ }^{1}$ Utah State University
}

January 5, 2021

\begin{abstract}
Irrigation activities are a major control on water movement and storage in irrigated river valleys in the Intermountain West, USA. Particularly in dry years, surface water diversions can deplete streams over the summer irrigation season, leading to more variable stream temperatures and increased risk for resident aquatic species. Cooler lateral inflows derived from irrigation activities can mitigate the impacts of depletion by buffering main channel stream temperatures. Given the increasing susceptibility of depleted streams to climate and land use changes, understanding stream temperature patterns and controls in these systems is critical. We used intensive field monitoring over three summers and thermal aerial imagery to characterize stream temperature patterns and irrigation influences in a $2.5 \mathrm{~km}$ reach of a small agricultural stream in northern Utah. Considering variable hydrology, weather, channel morphology, diversions, and lateral inflows we found stream temperatures to be relatively insensitive to flow depletion or lateral inflows in a wet year but very sensitive in drier years. Irrigation-related lateral inflows reduced longitudinal warming and diel variability during drier years and at times prevented temperatures from reaching stressful or lethal limits. Reaches with substantial lateral inflow contributions also had a greater areal proportion of low temperatures and spatial temperature diversity. These trends were enhanced by differences in channel morphology, with greater spatial and temporal variability in multi-thread than single-thread reaches. Study results highlight critical flow and weather conditions driving increased temperature variability that will likely become more extreme with additional climate change related reductions in baseflow. Regardless of the cause, this study highlights that decreased instream flows increase the importance of identifying, quantifying, and maintaining lateral inflows to maintain instream temperatures and preservation of these inflows should be considered in future water management decisions.
\end{abstract}

\section{Irrigation influences on summer stream temperature variability}

Key words: stream temperature; irrigation; surface heat fluxes; lateral inflows; thermal refugia

Running title: Irrigation influences on stream temperature variability

Authors: Sara M. Alger ${ }^{1}$, Belize Lane ${ }^{1 *}$, Bethany Neilson ${ }^{1}$

${ }^{1}$ Dept. of Civil and Environmental Engineering, Utah State University, Logan Utah USA

* Corresponding author, belize.lane@usu.edu

Acknowledgements: The authors would like to thank the Nibley City riparian landowners for providing access to the study reach. We also thank Utah State graduate students including Hyrum Tennant, Betsy Morgan, Jesse Rowles, and Daniel Thurber for their assistance with field data collection, and Jim DeRito of Trout Unlimited for his help with fish data collection and stakeholder collaboration. This work was supported in part by funding from the Utah Water Research Laboratory and the United States Geological Survey.

\section{Hosted file}

Alger-Manuscript-20201231 .pdf available at https://authorea.com/users/387347/articles/502480irrigation-influences-on-summer-stream-temperature-variability 

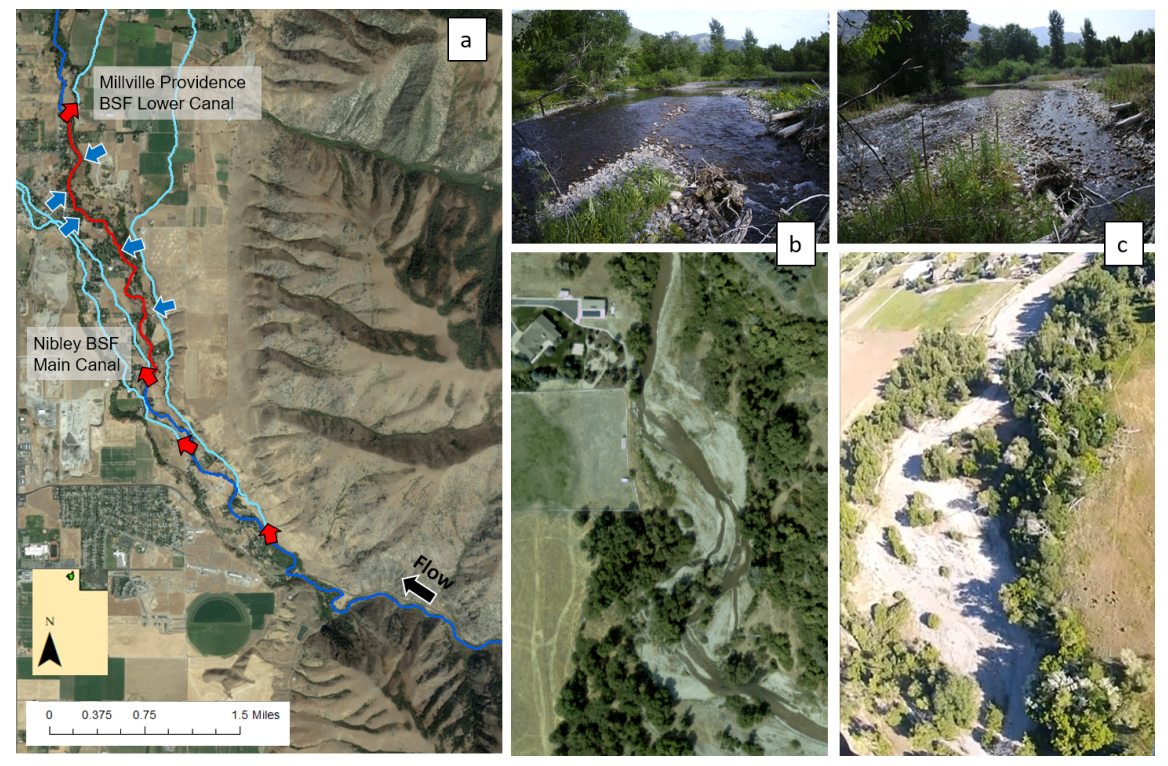


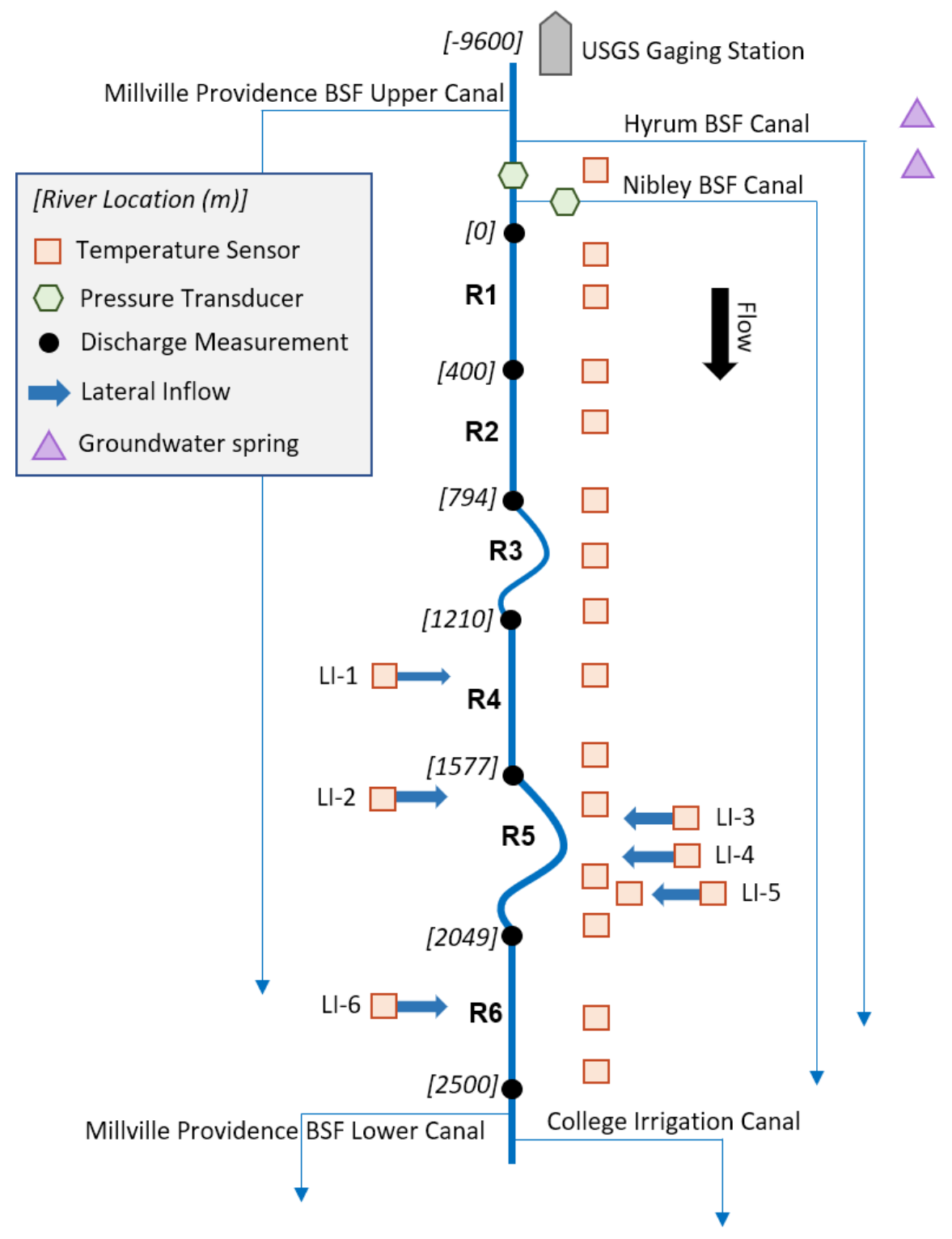



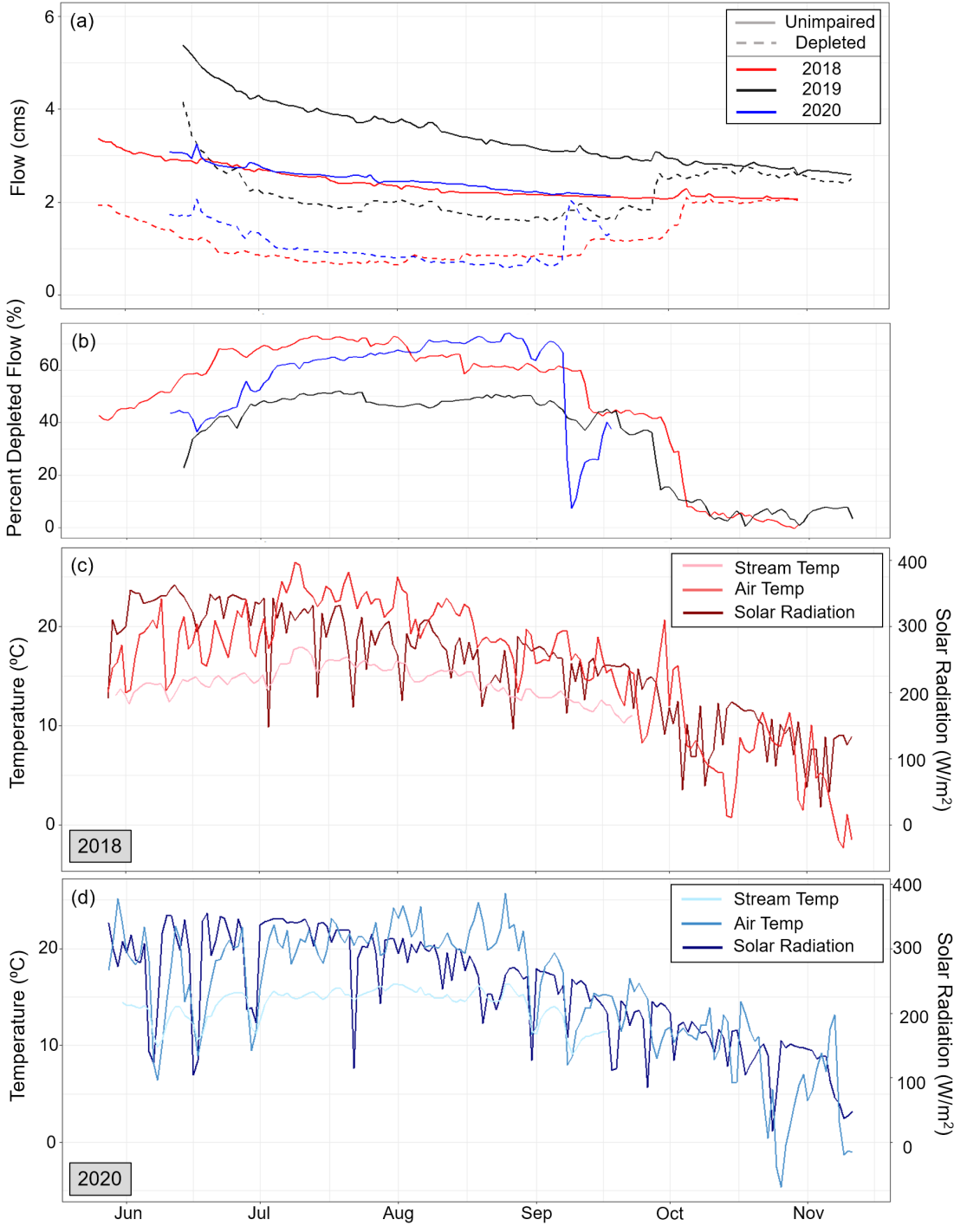

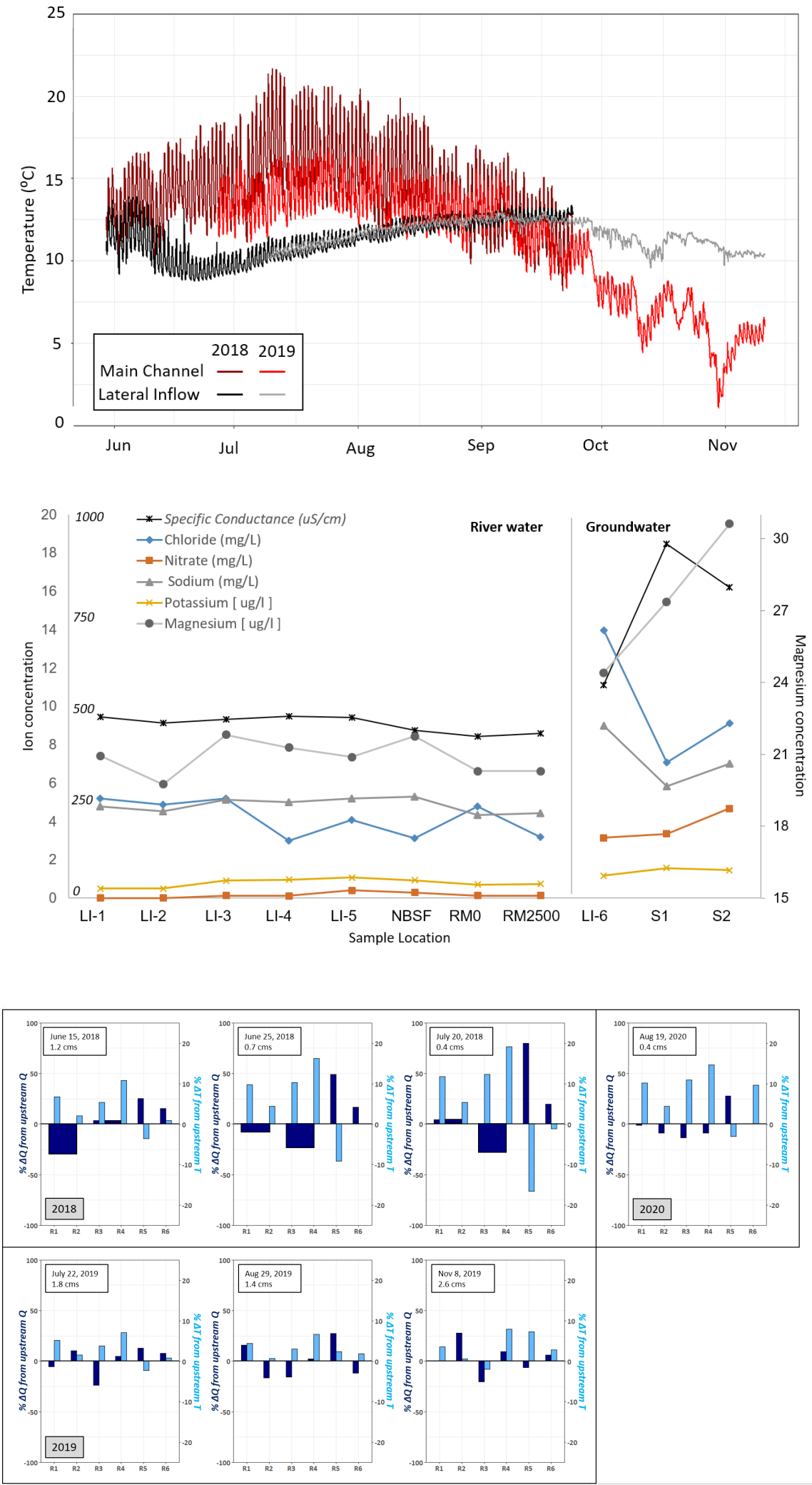

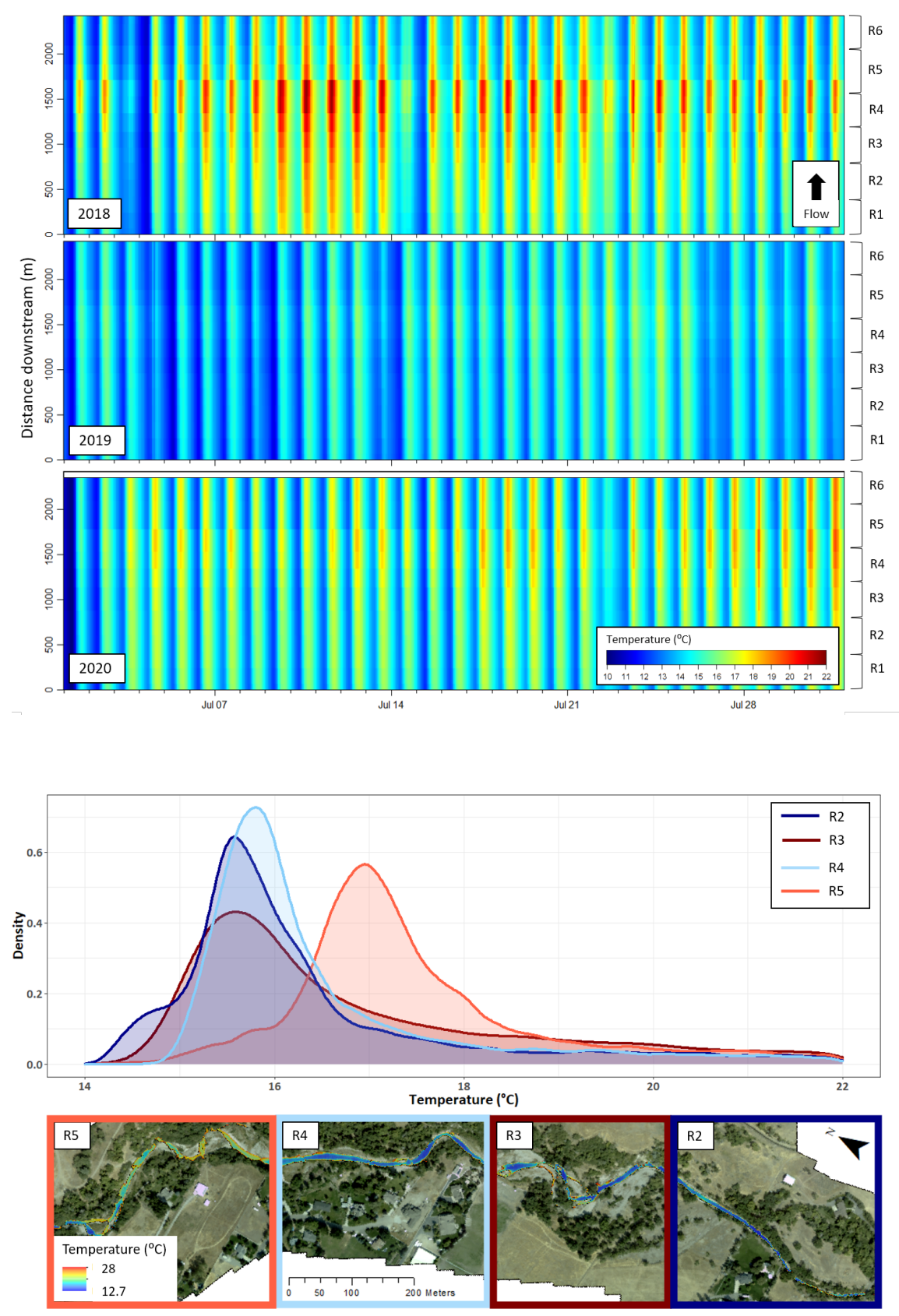

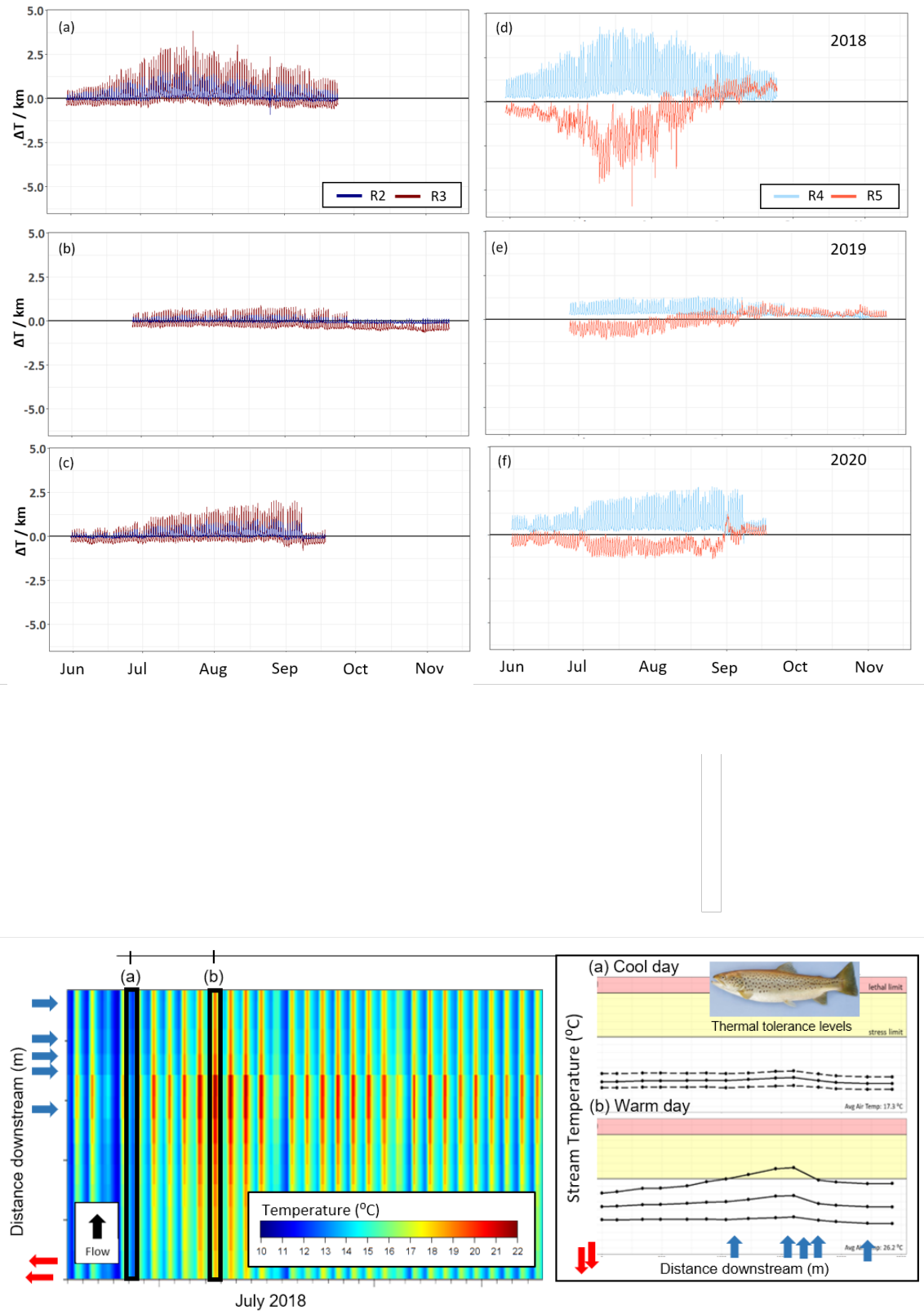